\title{
METÁFRASE E PARÁFRASE: MODALIDADES DA APROPRIAÇÃO DO DISCURSO DE OUTREM NA ESCRITA ACADÊMICA
}

\author{
Metaphrase and Paraphrase: Metafrasis y parafrasis: \\ Modalities for Appropriation of the Discourse modalidades de apropiación del discurso \\ of Other People in the Academic Writing de otros en la escritura académica \\ Bertrand Daunay* \\ Université de Lille, Centre Interuniversitaire de Recherche en Éducation, Lille, France
}

\begin{abstract}
Resumo: Como fazem os professores pesquisadores para retomar, em suas escritas, o discurso de outrem? Tal indagação questiona as modalidades da inserção de um discurso de outrem em um texto, diferenciando a metáfrase e a paráfrase (que dizem respeito a autonomia ou assimilação do discurso outro). A análise é contrastiva, visando identificar (em um corpus constituído de textos de colegas brasileiros de Linguística Aplicada e de colegas franceses de Didática) as diferenças de modalidades realizadas em textos de pesquisa e em textos de ensino. Os resultados da pesquisa confirmam a hipótese inicial: as modalidades enunciativas da inserção do discurso de outrem permitem, em certa medida, caracterizar genericamente discursos acadêmicos diferentes: os textos de ensino privilegiam a paráfrase, e os textos de pesquisa, a metáfrase.
\end{abstract}

Palavras-chave: Análise de discurso. Didática. Discurso de outrem. Enunciação. Letramento acadêmico.

\begin{abstract}
How do researchers do to take up again, in their writings, the discourse of other people? This paper analyses the modalities of insertion of other people's discourse in a text, by distinguishing metaphrase and paraphrase, which refer to the autonomy or assimilation of other people's discourse. We mobilize a contrastive analysis that investigates the different modalities conducted in research and teaching texts written by Brazilian Applied Linguistics colleagues and French didactics colleagues. The research results confirm the initial hypothesis: the enunciative modalities in the insertion of other peoples's discourse allow, to a certain extent, a generic characterization concerning different academic discourses: teaching texts privilege the paraphrase, and research texts privilege the metaphrase.
\end{abstract}

Keywords: Discourse analysis. Didactics. Enunciation. Other people's discourse. Enunciation. Academic literacy.

Resumen: ¿Cómo hacen los profesores investigadores para retomar, em sus escritos, el discurso del otro? La pregunta cuestiona las modalidades de inserción de un discurso de otro en un texto, diferenciando la metáfrasis y la paráfrasis (que dicen respeto a autonomía o asimilación del discurso otro). El análisis es contrastivo para identificar (en un corpus constituido de textos de compañeros brasileños de Lingüística Aplicada y de compañeros franceses de Didáctica) las diferencias de modalidades realizadas en textos de investigación y en textos de enseñanza. Los resultados de la investigación confirman la hipótesis inicial: las modalidades enunciativas de la inserción del discurso de otro permiten, em cierta medida, caracterizar genéricamente discursos académicos diferentes: los textos de enseñanza privilegian la paráfrasis, y los textos de investigación, la metáfrasis.

Palabras clave: Análisis del Discurso. Didáctica. Discurso de otro. Enunciación. Letramiento académico.

* Univ. Lille - Théodile-CIREL Centre Interuniversitaire de Recherche en Education de Lille (EA 4354),
F-59000 Lille, France. ORCID: https://orcid.org/0000-0002-3169-8515. E-mail: bertrand.daunay@univ-lille.fr. 
As palavras me antecedem e ultrapassam, elas me tentam e me modificam, e se não tomo cuidado será tarde demais: as coisas serão ditas sem eu as ter dito.

(Clarice Lispector, Os desastres de Sofia)

\title{
1 INTRODUÇÃO1
}

Como fazem os professores pesquisadores para retomar, nas suas escritas, o discurso de outrem? Tal indagação, que constitui o assunto deste artigo, questiona, de um modo específico e em um contexto particular, as modalidades da inserção do discurso de outrem em um texto, questão de relevância no campo do letramento acadêmico (entre outros, podemos citar alguns trabalhos, de disciplinas e países diversos, que mostram a importância dessa questão na abordagem do letramento acadêmico: ASSIS, 2018; BOCH, GROSSMANN, 2002; 2015; BOCH; RINCK, 2010; RINCK; BOCH; ASSIS, 2015; DELCAMBRE, 2001; FLØTTUM, 2005; HYLAND, 1999; RODRIGUES, 2016; TUTIN; GROSSMANN, 2013). A questão se refere a um problema mais geral de "heterogeneidade mostrada", apontado há muito tempo por Jacqueline Authier-Revuz (1982), ou do "discurso representado", conforme descrito pela ScaPoLine (NØLKE; FLØTTUM; NORÉN, 2004), último avatar de uma "teoria polifônica da enunciação" (DUCROT, 1984/1987, capítulo VIII). Essas abordagens especificam o fenômeno ainda mais global da polifonia estrutural que pode levar a considerar todo discurso, de certo modo, como um discurso de outrem (cf. BAKHTIN, 1934/1978; VOLÓCHINOV, 1929/2017).

Mesmo em uma concepção tão aberta de polifonia, os problemas enunciativos concretos da inserção efetiva de um dado discurso em um discurso outro foram analisados, nomeadamente, no fenômeno do discurso indireto livre. É assim que se pode ler, em Volóchinov (1929/2017, p. 250):

\begin{abstract}
O enunciado autoral que incorporou outro enunciado em sua composição elabora as normas sintáticas, estilísticas e composicionais para a sua assimilação parcial, para sua inclusão na unidade sintática, composicional e estilística do enunciado autoral, mantendo ao mesmo tempo, nem que seja de um modo rudimentar, a independência inicial (sintática, composicional e estilística) do enunciado alheio, sem a qual a sua integralidade seria imperceptível.
\end{abstract}

É essa questão do modo de simultaneamente manter a autonomia enunciativa do discurso de outrem e assimilá-lo que será tratada neste artigo ${ }^{2}$, com uma focalização em discursos específicos elaborados por professores pesquisadores, cujas escritas podem se caracterizar pela necessidade de inserir o discurso de outrem, na medida em que dessa atividade discursiva depende a construção de um conhecimento reconhecido em uma disciplina de pesquisa (HYLAND, 1999).

\footnotetext{
${ }^{1}$ Este artigo deve muito a Isabelle Delcambre, que participou da análise de um subcorpus, no primeiro passo da pesquisa (DAUNAY; DELCAMBRE, 2016; 2017); agradeço a ela por essa colaboração.

${ }^{2}$ Trata-se de uma perspectiva diferente e sobretudo muito mais modesta da de Volóchinov (2017), cuja abordagem histórica e filosófica da questão das "formas mais importantes de transmissão do discurso alheio" (p. 319), que visa "problematizar o fenômeno de transmissão do discurso alheio em uma perspectiva sociológica" (p. 247), com a análise dos "modelos sintáticos" (p. 246), ultrapassa a simples dimensão formal da inserção do discurso de outrem.
} 
A análise será contrastiva, uma vez que a questão implica dois polos (autonomia e assimilação do discurso de outrem) e impõe uma perspectiva até mesmo duplamente comparativa: a) trata-se de identificar se as modalidades da inserção do discurso de outrem realizadas em textos de pesquisa (destinados a uma comunidade científica) se diferem daquelas realizadas em textos de ensino (destinados a alunos), o que poderia ser um dos critérios distintivos de dois tipos de discursos diferentes; b) o âmbito de realização desta análise, uma pesquisa franco-brasileira, ${ }^{3}$ permitiu a constituição de dois subcorpora, a partir de textos fornecidos por colegas brasileiros (de Linguística Aplicada) e franceses (de Didática).

$\mathrm{Na}$ verdade, a única comparação sistemática realmente tratada aqui será aquela existente entre os discursos (de ensino ou de pesquisa), pois é fundada em hipóteses construídas teoricamente - que vamos apresentar mais adiante - sendo que o corpus analisado é demasiado amplo para autorizar conclusões empíricas; ao contrário, a comparação entre o Brasil e a França ou entre duas disciplinas diferentes (Linguística Aplicada e Didática) não está baseada em hipóteses pertinentes, tampouco em um corpus representativo, o que impede de serem tiradas conclusões relevantes. No entanto, essa variedade dos subcorpora assim constituídos permitirá levantar algumas sugestões para se construir novas hipóteses.

O trabalho apresentado neste artigo se inscreve na contribuição que nós fornecemos, no quadro do projeto de pesquisa franco-brasileiro já evocado, com relação ao subcorpus francês (DAUNAY; DELCAMBRE, 2016; 2017). Gostaria de agradecer a Isabelle Delcambre por ter consentido sobre o uso dos dados franceses já analisados por nós, que vou acrescentar aqui aos dados provenientes do subcorpus brasileiro - que constituí e tratei sozinho - com o intuito de propor uma reflexão original sobre a questão, inclusive no plano teórico ${ }^{4}$.

\section{METÁFRASE E PARÁFRASE: UM QUADRO DE ANÁLISE DAS MODALIDADES ENUNCIATIVAS}

As modalidades enunciativas devem ser entendidas no sentido básico que tomaremos de empréstimo de Charles Bally (1932/1962, p. 36): ele distingue, na análise de uma frase, o dictum, ou seja, o conteúdo representado, e o modus, que diz respeito ao posicionamento do sujeito em relação ao dictum. Deve-se dar duas precisões quanto às modalidades enunciativas aqui tratadas: a) são tipos específicos de modalidades, que reduzem a apreensão do fenômeno: tais modalidades são relativas a um contexto de escrita, mais especificamente de escrita acadêmica, dizendo respeito à inserção do

\footnotetext{
${ }^{3}$ Projeto CAPES-COFECUB (SH 834-15), dirigido por Juliana Assis e Sophie Bailly: "Discurso acadêmico na pesquisa e no ensino: questões em torno da apropriação da palavra de outrem" (2014-2018). A Universidade de Lille, envolvida nesse projeto, foi representada por Bertrand Daunay e Isabelle Delcambre.

${ }^{4}$ Gostaríamos, aqui, de agradecer aos colegas que aceitaram disponibilizar seus textos para constituir o nosso corpus. Agradecemos também pela ajuda, seja com a reflexão ou com a tradução, além de Isabelle Delcambre (cf. nota 1), a Arnaldo Rebello Camargo Junior, Daniel Bart, Denise Borille de Abreu, Francis Grossmann, Françoise Boch, Juliana Assis, Manoel Corrêa e Maria Angela Teixeira Lopes.
} 
discurso de outrem em um texto e às maneiras e aos graus da apropriação dele pelo escritor do texto $;^{5}$ b) mesmo que se realizem em formas linguísticas, como veremos, as modalidades não funcionam apenas no âmbito da frase ou no plano linguístico, mas dizem respeito a fenômenos discursivos e envolvem os sujeitos do discurso: o produtor que informa o seu posicionamento e o receptor que o interpreta.

Falamos anteriormente, citando Volóchinov, da dupla obrigação de manter a autonomia enunciativa do discurso de outrem e assimilá-lo ao discurso novo. Ora, podemos considerar que temos aqui dois polos e que a maneira de inserir o discurso de outrem no discurso novo pode favorecer mais a autonomia ou a assimilação. Chamemos esses dois polos, de acordo com Daunay e Delcambre (2016; 2017), respectivamente, de metáfrase e paráfrase. ${ }^{6}$

No primeiro caso, o discurso do escritor assume completamente a palavra de outrem, tornando-se o enunciador dela, por assim dizer; no outro polo, é o discurso de outrem que, de certo modo, governa a enunciação do discurso no qual é inserido - cujo enunciador praticamente se desvanece. A terminologia que propomos ${ }^{7}$ respeita a semântica dos prefixos, herdada do uso na língua grega antiga: a paráfrase expressa a proximidade enunciativa entre os discursos de origem e os de destino (este último se moldando à enunciação do discurso que o acolhe); já a metáfrase, por sua vez, expressa a distância, dado que o discurso selecionado não se funde na enunciação do discurso de destino: ela praticamente se apaga, dando lugar à enunciação daquele. Para ilustrar esses dois polos, veremos alguns exemplos a seguir, na descrição da metodologia da pesquisa.

Essas modalidades de gestão enunciativa do discurso de outrem não devem ser confundidas com as formas da inserção desse discurso: a distinção, como veremos, pode ser interessante. As modalidades são uma das formas retóricas da subjetividade do escritor, o que mostra, de modo mais ou menos visível, seu posicionamento em relação ao discurso do outro (cf. FLOREZ, 2013, sobre a reformulação e a citação posicionada), se aceitarmos a ideia de que, no campo científico mesmo, o sujeito pode falar. Apoiandose em diversos trabalhos (nomeadamente SWALES, 1990; FLØTTUM, DAHL; KINN, 2006; RINCK, 2006), Tutin e Grossmann (2013, p. 13; tradução nossa) lembram que a escrita acadêmica, em várias disciplinas, não pode ser descrita como um "gênero despersonalizado", caracterizado por um "forte apagamento enunciativo, no qual o autor se esconde por trás da apresentação de fatos objetivos e das modalidades de raciocínio compartilhadas pela comunidade científica". Na verdade, a retórica do discurso científico, em muitas disciplinas, é marcada por uma intenção argumentativa importante (DAUNAY; BART, 2019; POLLET; GLORIEUX, 2016) e por manifestações específicas de subjetividade (BOCH; RINCK, 2010, p. 6 sq.).

\footnotetext{
${ }^{5} \mathrm{Na}$ análise do corpus, o termo escritor designará, a partir de agora, o "locutor-enquanto-construtor" que “assume a responsabilidade pela enunciação" (NØLKE, FLØTTUM, NORÉN, 2004, p.30; tradução nossa), o que a ScaPoLine denomina de LOC (ibid.), retomando o L de Ducrot (1984/1987); o termo autor será usado para designar os responsáveis do textos cujos trechos foram retomados pelo escritor.

${ }^{6}$ Para uma genealogia dessa terminologia, que tomamos de empréstimo de uma distinção de Daunay (2002), com mudanças substanciáveis, cf. Daunay (2017).

${ }^{7}$ Se a combinação desses termos pertence à retórica antiga, para distinguir reformulações mais (paráfrase) ou menos (metáfrase) elaboradas (ROBERTS, 1985, p.26), cumpre ressaltar que ela não existe no campo da Linguística: a paráfrase é muito bem conhecida, ao contrário da metáfrase.
} 
Mais especificamente, no caso da apropriação do discurso de outrem nas escritas acadêmicas, reconhecendo as relações estritas entre a argumentação e o discurso representado (VINCENT; DUBOIS, 1997), podemos afirmar, de acordo com Doury (2004), que o discurso de outrem pode se tornar "um suporte da argumentação" do escritor e que as argumentações respectivas do escritor e do autor referido "podem se fundir em uma argumentação com coordenadas enunciativas vagas" (2004, p. 263; tradução nossa). As modalidades dessa fusão podem especificar as noções de metáfrase e de paráfrase.

Cabe precisar que tais modalidades não se confundem exatamente com as "posturas enunciativas", conforme descritas por Alain Rabatel (2004, 2007, 2016; cf. GROSSMANN; RINCK, 2004), ainda que as questões tratadas, no contexto do apagamento enunciativo, estejam relacionadas. Além da diferença de nível de apreensão do problema (Rabatel trata do discurso de maneira geral em várias realizações e não especificamente dos problemas particulares da apropriação do discurso de outrem), os fenômenos de co-, sub- ou super-enunciação, que ele propõe, dependem do ponto de vista construído pelo escritor e não se sobrepõem à paráfrase nem à metáfrase: por exemplo, $\mathrm{o}$ ponto de vista que pode ser identificado como sobranceiro pode se realizar, no plano enunciativo que tentamos descrever, tanto na metáfrase como na paráfrase.

A hipótese de nossa análise é que a questão das modalidades enunciativas da inserção do discurso de outrem - tais quais descritas anteriormente, em termos de paráfrase e metáfrase - pode ajudar quanto à caracterização de dois tipos de discursos escritos no contexto acadêmico: os discursos de pesquisa e os discursos de ensino. Tomemos de empréstimo as definições de Beacco e Moirand (1995), que distinguem: a) o "discurso de pesquisa" como "discurso primário" (p. 33), "cuja função é avançar os conhecimentos sobre um dado campo" (p. 40); b) o "discurso de ensino" (ou "discurso didático") como "discurso secundário" (p. 39), que "busca avançar os conhecimentos sobre o outro" (p. 40).

A relação entre esses dois discursos acadêmicos, para os autores, ocorre uma vez que os discursos de pesquisa, destinados a um público erudito de pares, são os "discursosfontes" dos discursos de ensino, que reformulam aqueles para públicos menos eruditos (1995, p. 39).

Tais descrições de Beacco e Moirand (1995, tradução nossa) se fundam sobre uma concepção temática ("os conhecimentos sobre um dado campo"/“sobre o outro"), textual ("primário" e "secundário", sinalizando uma relação intertextual entre os discursos) e pragmática (o leitor concebido sabe tanto ou menos que o escritor), o que, para nós, corresponde às definições tradicionais, respectivamente, do discurso explicativo (vide, por exemplo, BOREL, 1980) e argumentativo (por exemplo, PLANTIN, 1990; $2005 / 2008)^{8}$.

\footnotetext{
${ }^{8}$ Nesse passo da reflexão, cabe precisar que há um risco de reificação das categorias usadas: falamos de dois gêneros a priori, antes da nossa análise. Estamos diante, assim, de um risco real e um limite da pesquisa, todavia assumidos, uma vez que tratamos de textos que os autores mesmos designaram como textos de ensino ou de pesquisa.
} 
Nessa perspectiva, a propósito da inserção do discurso de outrem, nossa hipótese é de que o escritor não implementa exatamente as mesmas normas nos discursos em jogo: postulamos que, nos textos de ensino, a paráfrase deveria prevalecer sobre a metáfrase, na medida em que naqueles o que mais importa é uma apresentação dos autores e suas ideias/conceitos aos estudantes, apagando, assim, o escritor; ao contrário, nos textos de pesquisa, a metáfrase prevaleceria sobre a paráfrase, na medida em que neles importa mais a argumentação do escritor.

Em nossos trabalhos anteriores (DAUNAY; DELCAMBRE, 2016; 2017), a respeito de um subcorpus francês de textos provenientes da disciplina de Didática, pudemos verificar essa hipótese: percebe-se uma clara fronteira entre os discursos, sendo que a diferença de modalidades de acordo com os escritos seria explicada pela dissociação entre o que é da ordem da argumentação e da teoria (textos de pesquisa) e o que é da ordem da prescrição ou da extensão (textos de ensino).

Gostaríamos, aqui, de retomar a análise com um corpus maior, incluindo textos de professores pesquisadores brasileiros de Linguística Aplicada. Conforme afirmamos anteriormente, não será possível construir uma comparação sistemática entre o subcorpus brasileiro e o francês: além da fraca representatividade e da heterogeneidade dos dados, não construímos hipóteses que poderiam justificar uma comparação. Para isso, teria sido necessário, sob a perspectiva da análise do discurso, descrever um arquivo e uma formação discursiva, retomando as palavras de Maingueneau $(1991 ; 2006)$ - que ele, por sua vez, tomou de empréstimo de Foucault (1969/2012) - para "considerar as Ciências Humanas e Sociais em sua conjuntura política, histórico-social, assim como na perspectiva das formas materiais das discursividades" (ORLANDI, 2017, p. 258). Não é esse o nosso projeto e não se trata aqui da questão "de se mundializar ou não as ciências e os pesquisadores" (ORLANDI, 2017). Sendo assim, apenas identificaremos com prudência, se for o caso, algumas tendências que mostram diferenças entre os dois subcorpora, tratando-os, sobretudo, como um todo.

\section{METODOLOGIA DE COLETA E DE TRATAMENTO DE DADOS}

Sem repetir em pormenor a descrição da metodologia adotada na pesquisa, já detalhada em trabalhos prévios (DAUNAY; DELCAMBRE, 2016; 2017), vamos indicar o que é preciso para entender a nossa abordagem ou o que é específico ao novo subcorpus analisado.

Para facilitar a comparação entre os textos de ensino e de pesquisa, os formatos foram limitados: os primeiros são textos escritos (ou slideshows) constituídos de palestras realizadas em cursos a distância; as produções de pesquisa selecionadas são artigos de periódicos e capítulos de livros. Todos os textos foram escritos entre 2009 e 2017, o que corresponde à amplitude do subcorpus brasileiro, sendo a do subcorpus francês a mais curta (entre 2014 e 2015). 
Por várias razões de homogeneidade do corpus, devemos fazer uma seleção dos textos coletados: ao final, foram selecionados os textos de seis professores pesquisadores, com uma disparidade entre o Brasil e a França, uma vez que foram selecionados os textos de quatro franceses e dois brasileiros. O tamanho do corpus total contém quase mil páginas e pode ser descrito objetivamente no quadro 1 a seguir: ${ }^{9}$

\begin{tabular}{|l|l|r|r|}
\cline { 3 - 4 } \multicolumn{2}{|c|}{} & Número de palavras & $\begin{array}{c}\text { Número de caracteres } \\
\text { (com espaço) }\end{array}$ \\
\hline \multirow{3}{*}{ Textos de ensino } & BR & 42.491 & 282.562 \\
\cline { 2 - 4 } & FR & 91.148 & 598.573 \\
\cline { 2 - 4 } Textos de pesquisa & Total & $\mathbf{1 3 3 . 6 3 9}$ & $\mathbf{8 8 1 . 1 3 5}$ \\
\cline { 2 - 4 } & FR & 41.535 & 278.487 \\
\cline { 2 - 4 } & Total & 100.342 & 658.611 \\
\hline TOTAL & & $\mathbf{1 4 1 . 8 7 7}$ & $\mathbf{9 3 7 . 0 9 8}$ \\
\hline
\end{tabular}

\section{Quadro 1 - Tamanho do corpus}

Não nos importa constatar que o tamanho do subcorpus brasileiro seja menor que o subcorpus francês (na verdade, o primeiro representa quase $45 \%$ do segundo), posto que não faremos, salvo à margem, uma comparação dos dois subcorpora; o tratamento dos dados será unificado.

Uma vez constituído o corpus, foi necessário identificar, nos textos selecionados, as passagens (em regra geral, segmentos correspondentes a frases entre dois pontos ou orações entre dois pontos-e-vírgulas) que representam um discurso de outrem: em uma lógica de "heterogeneidade mostrada" (AUTHIER-REVUZ, 1982), não se tratando de uma polifonia difusa, mas da apropriação explícita de palavras de outrem.

Os autores podem ser identificados (conforme a grande maioria das ocorrências), mas há também "autores" anônimos, como no trecho que segue:

Web 2.0 é expressão popular que designa versão da internet caracterizada por interface amigável, dinamicidade, compartilhamento, colaboração na distribuição de conteúdos disponíveis. [BR2P2]

ou campos científicos, como neste extrato:

\footnotetext{
${ }^{9}$ Aqui está a codificação utilizada, empregada doravante no artigo: BR e FR designarão, respectivamente, os textos brasileiros e franceses. Quando forem citados extratos do corpus, além dessas letras, um primeiro número distinguirá os indivíduos; uma letra a mais, a natureza da escrita (E para ensino, $\mathrm{P}$ para pesquisa); um número final identificará o documento próprio (por exemplo, BR1E1 e BR2P2 referemse, respectivamente, ao primeiro texto de ensino do professor pesquisador BR1 e ao segundo trabalho de pesquisa do professor-pesquisador BR2). É preciso acrescentar que nenhuma alteração será feita nos extratos do corpus original, salvo os destaques em negrito, que serão usados para marcar um fenômeno enunciativo.
} 
Em especial, a Análise do Discurso, ao focalizar a interação, tem investido esforços nos estudos das emoções, tomando-as como constitutivas das relações de troca, numa abordagem discursiva. [BR1P1]

e mesmo discursos sociais anônimos, nos quais a voz é claramente identificada, conforme segue:

Web 2.0 é expressão popular que designa versão da internet caracterizada por interface amigável, dinamicidade, compartilhamento, colaboração na distribuição de conteúdos disponíveis. [BR2P2]

O número dos enunciados assim identificados é de 1.988 (1.337 para o subcorpus francês e 651 para o brasileiro, em uma proporção idêntica ao tamanho do corpus inteiro). Após a identificação das passagens do discurso representado, e antes da identificação, nelas, das modalidades, gostaríamos de detectar as formas das apropriações, segundo a tipologia de Boch e Grossmann (2002), que adaptamos. Para nós, foi possível identificar cinco formas (em vez de quatro, como para Boch e Grossmann), que vamos apresentar rapidamente com exemplos do nosso subcorpus brasileiro:

(1) A citação, marcada por meios tipográficos (em geral, aspas ou itálico). Eis um exemplo típico:

Para ele, emoções "são dinâmicas corporais que especificam os domínios de ação em que nos movemos" (MATURANA, 2005, p. 92). [BR1P1]

(2) A reformulação, que consiste em uma apropriação do conteúdo e não da forma textual do discurso de outrem, quase em um discurso indireto ou indireto livre, sem marca tipográfica específica, mas com sinais de atribuição das palavras a um autor exterior ("segundo X", "para Y", "Z afirma que" etc.). Um exemplo típico seria:

Assim, Gil (1999) define método científico como um conjunto de procedimentos intelectuais e técnicos adotados para se atingir o conhecimento. [BR1E1]

(3) A evocação: pode-se considerar como tal uma passagem na qual "o escritor faz alusão a trabalhos sem pretender resumir seu teor" (BOCH e GROSSMANN, 2002, p. 100). Trata-se de uma forma facilmente reconhecível quando há muitas referências, conforme segue:

Levando-se em conta o chamado ciberativismo e possibilidades de utilização das tecnologias do momento, em particular, dispositivos móveis como tablets e smartphones, talvez o ideal do cineasta não esteja distante (ver CASTELLS, 2013; MALINI, ANTOUN, 2013). [BR2P2] 
Consideramos, também, como evocações as passagens nas quais a identificação condensada do conteúdo do discurso de outrem não é acompanhada de precisões sobre esse conteúdo, tal como no seguinte enunciado:

De nosso ponto de vista, elas têm uma proximidade com a abordagem paradigmática da informação apresentada por CAPURRO (2003). [BR2P2]

Aqui está um exemplo que permite visualizar a dificuldade de confiar a identificação das formas das apropriações a uma análise automática: a intuição do pesquisador se faz necessária nesses casos.

Além dessas três formas tradicionais que Boch e Grossmann retomam em sua tipologia, os autores propõem uma quarta forma, a "ilhota citacional", a qual optamos por não adotar, mas, sim, por dividi-la em duas outras formas, a saber:

(4) O empréstimo: chamamos assim uma citação curta: uma palavra ou um sintagma. Por exemplo:

ênfase no visível (no "mostrado marcado") da linguagem (CORRÊA, 2016). [BR2E1]

(5) A hibridação: para nós o que se assemelha ao empréstimo, mas dentro de uma reformulação. Segue, aqui, um exemplo claro:

\footnotetext{
Quanto à terceira dimensão, o trabalho real, refere-se também às "atividades contrariadas", destacando as tensões sofridas pelo trabalhador, quando é impedido, por diferentes fatores, de realizar o trabalho prescrito (CLOT, 1999, p. 23). [BR1P3]
}

Lembremo-nos de que, para as formas de empréstimo, hibridação ou citação, é preciso ter a presença, ao mesmo tempo, de marcas tipográficas (como aspas) e uma referência explícita a um autor (ou a um campo). Assim, as aspas que indicam uma distância, uma insistência ou uma referência a um discurso comum não são selecionadas, como no exemplo a seguir:

qual é a produtividade dessas orientações no que se refere a uma reflexão sobre concepção de "outro" (texto, autor) em práticas letradas acadêmicas [BR2E1]

Essas formas não devem se confundir com as modalidades, que constituem o tópico principal de nosso trabalho, conforme iremos demonstrar agora - mas julgamos por bem apresentar as formas, precisamente para mostrar a diferença entre formas e modalidades, conforme explica a nossa pesquisa.

Com efeito, após as formas, identificamos as modalidades de todos os enunciados selecionados como representando um discurso de outrem. Essa identificação é mais difícil do que a das formas, uma vez que não se trata, aqui, de categorias exclusivas, mas de uma escala, entre os dois polos da metáfrase e da paráfrase, com muitos graus de gestão enunciativa do discurso de outrem, assumindo mais ou menos o escritor. Ao invés desse continuum, que seria impossível analisar, escolhemos adotar uma escala de cinco graus: 


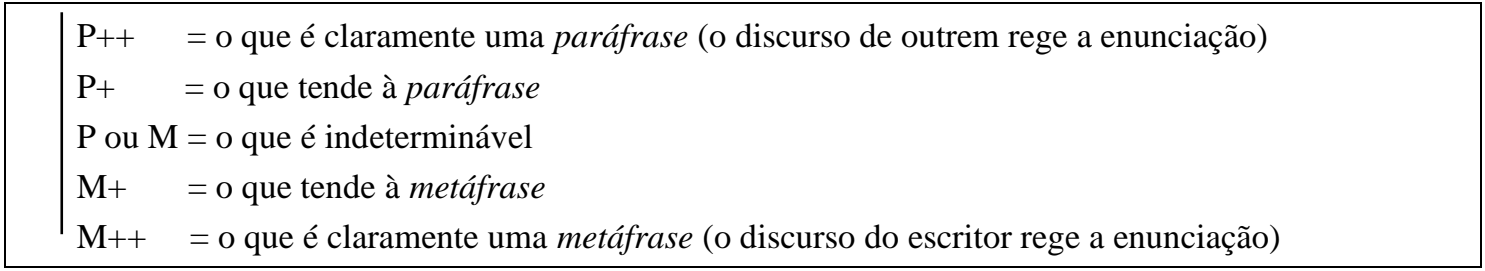

\section{Quadro 2 - Escala entre metáfrase e paráfrase}

Não é possível fazer aqui uma lista dos marcadores das modalidades, que permitem uma certa regularidade na codificação dos enunciados, mas seguem alguns exemplos desses marcadores.

Quanto à metáfrase, indicamos a referência a várias passagens de um texto de um autor, a várias referências de um autor ou, a fortiori, a referências de vários autores:

Em sua pesquisa sobre escrita na universidade, Delcambre e Lahanier-Reuter (2015, p. 228, 241) apresentam dificuldades enfrentadas e esforços empreendidos por pesquisadores (em particular, os chamados "em formação") de Ciências Humanas. [...] [BR3E1]

Ressaltamos, ainda com STREET (2007), que práticas de leitura e escrita em contexto digital são práticas sociais atravessadas por questões de poder e identidade, segundo "modelo ideológico" (STREET, 1984), que busca reconhecer multiplicidade e complexidade de sua constituição, "não [...] simplesmente tecnologias neutras" (STREET, 2007: 466). [BR3P2]

Nas últimas décadas, as pesquisas dedicadas à didática da escrita, em destaque as realizadas por Schneuwly e Dolz (2010) Machado, Lousada e Abreu-Tardelli (2005), Bronckart (2015) têm ganhado relevância nos contextos universitários nacional e internacional, fato convergente com a constatação de que o domínio da escrita alfabética não garante as competências de ler e escrever eficientemente e de que o êxito no Ensino Superior está muito atrelado ao domínio desses modos de dizer. [BR1P2]

É o caso, também, das referências múltiplas na evocação de uma lista de autores (muitas vezes entre parênteses e introduzidas por ver ou $c f$.):

Ao se analisar um evento interacional, devem-se considerar os sujeitos envolvidos no processo, suas representações sociais, suas faces, seus enquadres e seus footings (GOFFMAN, 1998, 2009, 2011; JODELET, 2002; MOSCOVICI, 2003). [BR1E2]

Próximos desse caso, os resumos de trabalhos diversos:

Outro psicólogo, o francês Henri Wallon (1984), em suas pesquisas sobre crianças lesadas neurologicamente, concorda com o posicionamento de Vygotsky, tomando a emoção como algo biológico e social. [BR1P1]

Uma outra série de marcadores de metáfrase são as marcas de apropriação das palavras de outrem pelo escritor, mais especificamente no caso da inserção de uma apropriação através de uma oração subordinada, estando o discurso de outrem estreitamente interligado com a argumentação do escritor:

Procuramos destacar, ao final, que, de uma perspectiva etnográfica e discursiva (CORRÊA, 2011), não há brechas para que a informação seja concebida como "coisa" (BUCKLAND, 1991) acessada e armazenada pelo indivíduo, assim como não há espaço para que, numa cultura participativa (JENKINS ET AL., 2006) ou de produzagem (BRUNS, 2006), haja controle de informação (dos sentidos). [BR2P2] 
Aqui se pode ver como o escritor mistura vozes múltiplas, praticamente inseridas na sua própria argumentação e no seu próprio sistema enunciativo - exemplo claro de discurso multireferenciado, conforme descreveu Grossmann (2002).

Um marcador próximo daquele é a apresentação de uma apropriação por meio de uma expressão tal qual como diria $X$, na qual o futuro do pretérito estabelece uma distância da enunciação do autor citado para melhor integrar o conteúdo no discurso do escritor (a partir de agora, destacamos em negrito as expressões afetadas) ${ }^{10}$.

[...]a informação é concebida como algo objetivo, como "coisa", qualquer coisa, que pode ser tanto armazenada quanto recuperada pelo indivíduo, não havendo, desse modo, espaço para a participação daquele que da "coisa informativa" tentaria se apropriar, como se supõe em JENKINS ET AL. (2006) e em JENKINS (2009). [BR2P2]

Uma terceira série de marcadores consiste na fusão dos discursos, que podem ser vistos por meio da mudança de sentido dos conectivos ou das anáforas das palavras de outrem integradas ao texto do escritor. Por exemplo:

Nessa esteira de reflexão, destacamos, com PÊCHEUX (2011), que o deslocamento da forma (dada) para o sentido (construído) da informação é uma característica, ou propriedade, para usar os termos de PÊCHEUX, "do campo da análise de discurso, que se diferencia por essa razão mesma de toda perspectiva estritamente informacional, documentária ou intelectiva" (2011: 281). [BR2P2]

Por essa razão mesma trata-se de uma anáfora que se refere a um cotexto diferente do que o de origem: certamente, a reformulação ocorre na lógica do discurso apropriado, mas vê-se bem como o texto do escritor faz ressoar uma passagem do texto apropriado em sua própria enunciação, que rege a voz de outrem.

Outras marcas de distância, como as modalizações, permitem identificar uma dimensão metafrástica:

Para BRUNS (2006: 2), num modelo econômico pósindustrial, a produção de ideias emergiria em contexto participativo. [BR3P2]

Além disso, podemos sinalizar os julgamentos de valor (positivos ou negativos) e o destaque (em itálico, por exemplo) pelo escritor de palavras apropriadas. Por fim, uma outra marca, dentre outras, de distância metafrástica: a referência ao que não diz o discurso de outrem, conforme segue:

JENKINS (2009) e BRUNS (2006), por exemplo, não discutem o fato de que nessa cultura de convergência a noção de participação passe pela ideia de ser consumidor. [BR3P2]

Todos os exemplos propostos não realizam necessariamente uma metáfrase classificada no último grau da escala, mas identificam a possibilidade de uma interpretação mais metafrástica da passagem.

Após os exemplos de marcadores de metáfrase, vamos aos marcadores de paráfrase.

${ }^{10}$ Neste exemplo e nos que segue, destacamos o marcador da modalidade. 
Consideremos esta passagem, que vem a ser um exemplo de título de anexo em um texto que descreve as normas da escrita acadêmica:

\section{ANEXO A - NORMAS INTERNAS DA ESCOLA INVESTIGADA. [BR1E1]}

Nessa expressão, em maiúsculas, totalmente livre, sem nada para acompanhá-la, a enunciação do autor retomado ocupa todo o espaço, até mesmo a enunciação do escritor que cita a expressão. Trata-se de um exemplo típico de paráfrase, que se realiza da mesma maneira no caso da epígrafe ou das citações no discurso direto, sem que seja preciso dar exemplos.

A apresentação do discurso, retomado com expressões tais quais segundo $X$ ou como diz $Y$, permite ao escritor fundir sua própria enunciação com a do discurso apropriado, como neste exemplo:

Segundo JENKINS (2009: 30), "alguns consumidores têm mais habilidades para participar dessa cultura emergente do que outros". [BR3P2]

Uma outra forma de fusão da enunciação do escrito com a do discurso apropriado: o fato de o escritor construir uma frase para dar lugar a palavras de outrem, como no exemplo seguinte, no qual o que diz textualmente um autor (em itálico) é introduzido por um verbo do escritor:

há negação do trabalho estilístico na produção científica [BR2E1]

É preciso lembrar, uma outra vez, que falamos de uma escala com graus entre dois polos, a metáfrase e a paráfrase. Portanto, marcadores de metáfrase podem levar a classificar como $\mathrm{P}+$ uma passagem que poderia assemelhar-se a uma paráfrase pura $(\mathrm{P}++)$. Vejamos o próximo exemplo:

Numa abordagem filosófica sobre a noção de informação, VINÍCIOS SOUZA DE MENEZES (2015: 8) destaca que: "A palavra informação assinala para uma dupla direção: a privação da forma, que significa palavras como informis (e), informitas, informiter, informabilis, e a doação da forma, como em informo, informas, informare, informavi, informatum, informator." [BR3P2]

Sem o início (em negrito), essa passagem poderia parecer uma paráfrase pura $(\mathrm{P}++)$; mas foi registrado $\mathrm{P}+$, pois a voz do autor intervém para indicar a origem da citação, o que vem a ser uma marca de metáfrase, que, combinada à paráfrase, faz com que a dimensão parafrástica da passagem desça um grau.

É possível, de fato, que os marcadores de metáfrase e de paráfrase se neutralizem: no caso de haver interligação entre duas modalidades enunciativas, a dimensão metafrástica ou parafrástica pode ser indeterminável (na escala, é o que corresponde ao código "P ou M"), tal como se dá nesta passagem: 
Não se trata, portanto, de "um simples meio de transmissão do discurso, [já que] ele imprime um certo aspecto a seus conteúdos e comanda os usos que dele podemos fazer" (MAINGUENEAU, 2008: 71). [BR3P2]

Aqui, um marcador de paráfrase, a citação em discurso direto, entra em concorrência com dois marcadores de metáfrase (em negrito): a introdução das palavras e a intervenção do escritor na citação; isso explica que essa passagem tenha sido classificada como "P ou M".

Cabe precisar, como já vimos no caso das formas, que a determinação da dimensão metafrástica ou parafrástica dos enunciados depende, evidentemente, da interpretação e da intuição do pesquisador, que não pode ser substituído por uma máquina... É por isso que, tanto na identificação dos enunciados quanto na determinação das formas e das modalidades das apropriações, trabalhamos conjuntamente, com Isabelle Delcambre, no subcorpus francês, a fim de estabilizar os critérios e verificar nossas respectivas intuições.

\section{ALGUNS RESULTADOS}

Antes de chegar ao objeto principal da nossa pesquisa, consideramos que poderia ser interessante mostrar um resultado induzido no tratamento dos dados: a densidade da apropriação do discurso de outrem nos textos do corpus, o que permite assinalar a importância daquele nos textos acadêmicos. No quadro 3 que segue, a densidade corresponde à proporção dos caracteres das passagens apropriadas em relação ao número de caracteres do corpus total:

\begin{tabular}{|c|r|r|r|}
\cline { 2 - 4 } \multicolumn{1}{c|}{} & \multicolumn{1}{c|}{ Corpus } & Apropriações & Percentual \\
\hline \multirow{3}{*}{ Textos de ensino } & 881.135 & 131.849 & $\mathbf{1 4 , 9 6}$ \\
& BR: 282.562 & BR: 47.133 & BR: 16,68 \\
& FR: 598.573 & FR: 84.716 & FR: 14,15 \\
\hline \multirow{4}{*}{ Textos de pesquisa } & 937.098 & 362.358 & $\mathbf{3 8 , 6 7}$ \\
& BR: 278.487 & BR: 115.838 & BR: 41,60 \\
& FR: 658.611 & FR: 246.520 & FR: 37,43 \\
\hline \multirow{2}{*}{ Total } & 1.818 .233 & 494.207 & $\mathbf{2 7 , 1 8}$ \\
& BR: 561.049 & BR: 162.971 & BR: 29,05 \\
& FR: 1.257 .184 & FR: 331.236 & FR: 26,35 \\
\hline
\end{tabular}

Quadro 3 - Densidade da apropriação (número de caracteres - com espaço)

Conforme se vê no quadro 3,27,18\% da superfície dos textos, em média podem ser considerados como apropriações do discurso de outrem, com uma diferença visível entre textos de ensino (14,96\%) e de pesquisa $(38,67 \%)$. A tendência é a mesma nos subcorpora brasileiro e francês, com uma ênfase no primeiro. ${ }^{11}$ Podemos ver, aqui, uma primeira característica distintiva dos dois tipos de discursos em jogo.

\footnotetext{
${ }^{11}$ Cumpre precisar, aqui, que os resultados não diferem muito entre os escritores: é por isso que podemos propor resultados globais, sem identificar as variações interindividuais.
} 
Uma outra característica desses gêneros pode ser identificada nas modalidades das apropriações das palavras de outrem, de acordo com a nossa hipótese: a análise dos dados dos dois subcorpora mostra, como na análise dos dados franceses (DAUNAY; DELCAMBRE, 2016; 2017), uma prevalência da paráfrase nos textos de ensino e da metáfrase nos textos de pesquisa, conforme o gráfico 1, no qual a porcentagem é calculada a partir dos enunciados:

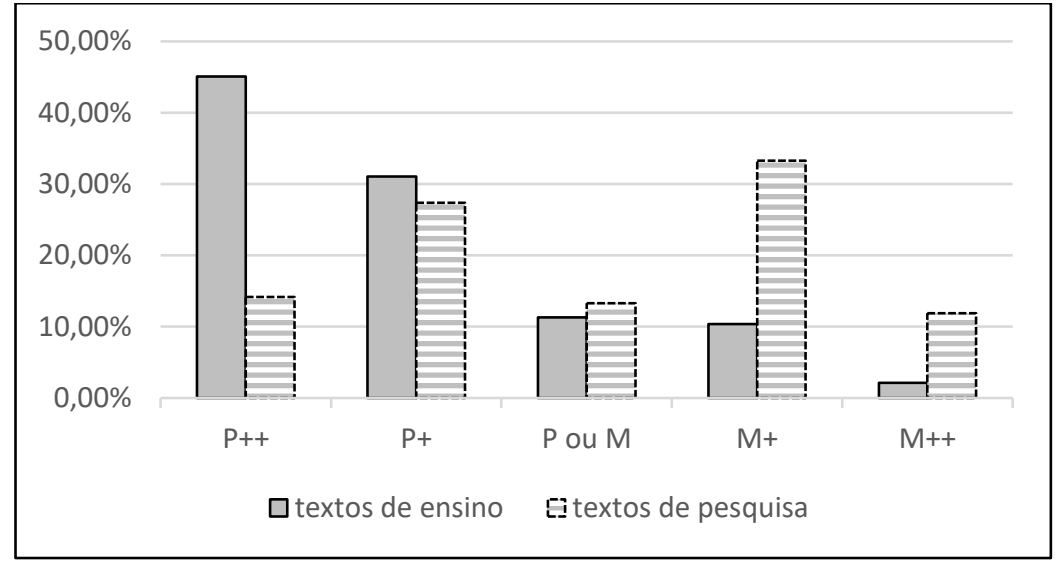

Gráfico 1 - Taxa das modalidades em relação às apropriações totais

A tendência, que foi já identificada no subcorpus francês (DAUNAY; DELCAMBRE, 2016; 2017), é clara: a paráfrase domina nos textos de ensino $(45,11 \%$ dos enunciados podem ser considerados como realizando uma paráfrase importante: $\mathrm{P}++)$, ao passo que a metáfrase domina nos textos de pesquisa $(33,28 \%$ dos enunciados podem ser considerados como realizando uma metáfrase). Tal tendência se faz ainda mais evidente nos textos de ensino, ao se calcular o conjunto dos valores dos polos $(\mathrm{P}++/ \mathrm{P}+\mathrm{e}$ $\mathrm{M}++\mathrm{M}+): 76,15 \%$ dos enunciados foram identificados como paráfrase, contra $12,54 \%$ de metáfrase (mas cabe notar que os valores se equilibram nos textos de pesquisa: respectivamente $41,53 \%$ e $45,20 \%$ ).

O gráfico 2, a seguir, demonstra que não há uma diferença significativa entre os subcorpora brasileiro e francês:

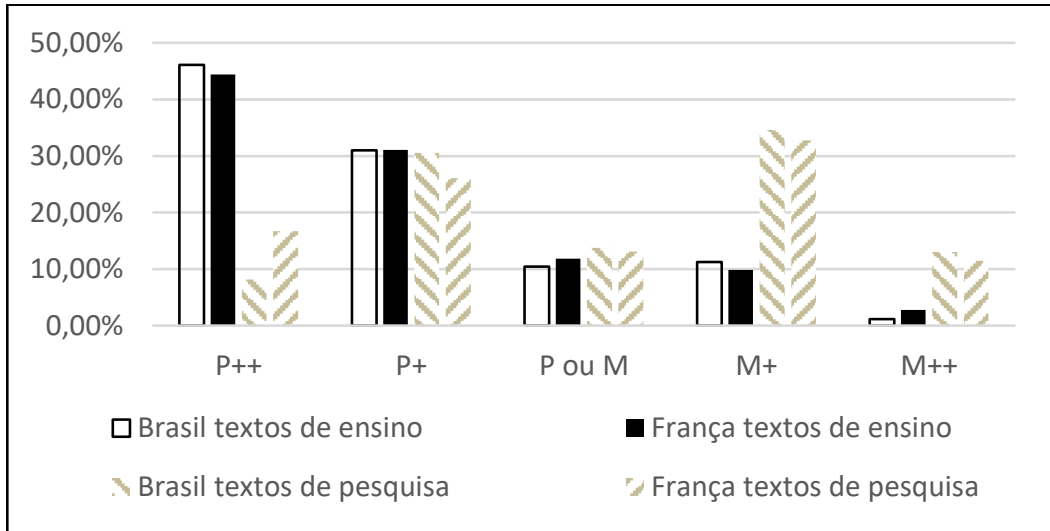

Gráfico 2 - Taxa das modalidades (comparação dos subcorpora brasileiro e francês) 
Pode-se ver, neste gráfico, que a importância respectiva de cada modalidade no discurso de ensino e no discurso de pesquisa é a mesma nos dois subcorpora brasileiro e francês. Como já dissemos, não há possibilidade de tirar conclusões dessa observação, mas ela pode explicar nossa escolha de tratar os dados juntos para dar uma major amplitude à amostra, o que permite melhor ressaltar as diferenças entre os dois tipos de discursos, cuja comparação foi o objeto principal da análise aqui apresentada.

Nossa pesquisa visou identificar as modalidades independentemente das formas de apropriação do discurso de outrem, porque pensamos ver entre aquelas uma diferença. Essa hipótese se confirma parcialmente, mas não totalmente. Com efeito, há uma relação entre certas formas e certas modalidades, como pode se ver no gráfico 3, no qual a diferença entre os textos de ensino e de pesquisa, no plano das formas, pode se sobrepor à diferença entre os textos no plano das modalidades:

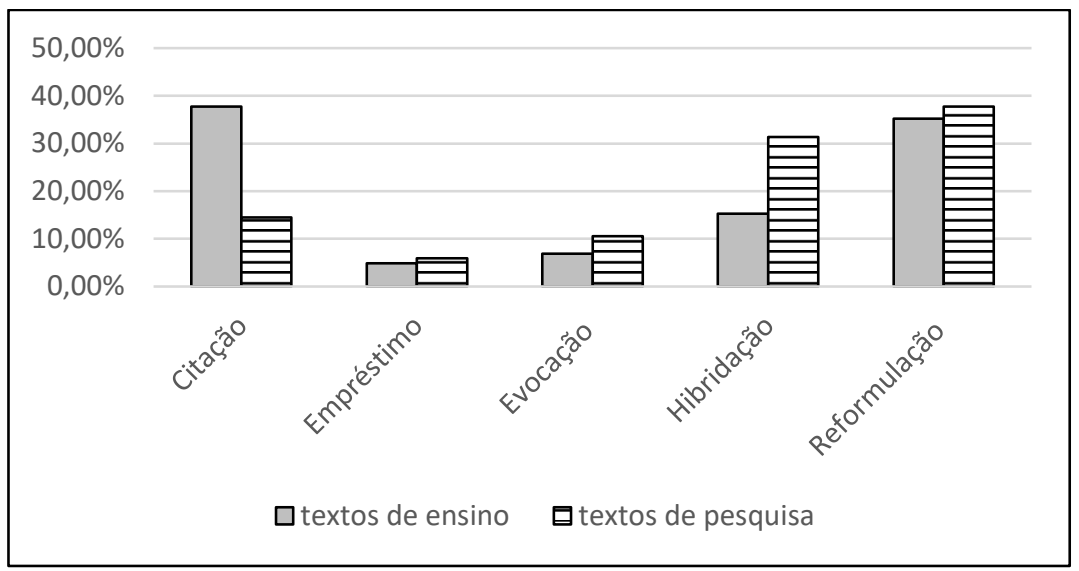

\section{Gráfico 3 - Taxa das formas (todos os subcorpora em conjunto)}

O gráfico 3 mostra que os textos de pesquisa utilizam, mais do que os textos de ensino, a forma da hibridização, enquanto os textos de ensino utilizam mais do que os textos de pesquisa a forma da citação; talvez, essa possa ser considerada como sendo mais didática no sentido de que pareceria mais fiel à ideia subjacente ao excerto citado e daria margem a menos ambiguidades - mas isso é uma representação que não prejudica a realidade da fidelidade, no plano do enunciado e, sobretudo, no plano da enunciação...

A comparação entre os dois últimos gráficos pode sugerir uma relação entre as formas e as modalidades das apropriações do discurso de outrem. Estabelecemos, de fato, uma forte solidariedade entre a forma citação e a modalidade paráfrase ou, ainda, entre a forma hibridação e a modalidade metáfrase. Assim, sem distinguir os subcorpora (textos de ensino e de pesquisa; textos brasileiros e francês), com o intuito de evitar a multiplicação das cifras, observamos que $75 \%$ dos enunciados identificados como citações foram também identificados como $\mathrm{P}++$ (e 91,14\% das citações são $\mathrm{P}++$ ou $\mathrm{P}+$ ); por outro lado, 38,22\% enunciados identificados como hibridações foram também identificados como $\mathrm{M}+(58,11 \%$ como $\mathrm{M}+$ ou $\mathrm{M}++)$. Entre esses dois polos extremos prevalece uma regularidade maior, mas cumpre notar também, logicamente, uma solidariedade entre a reformulação e a paráfrase $(53,62 \%$ das reformulações foram identificadas como $\mathrm{P}+$ ou $\mathrm{P}++$ ). 
Entretanto, prevalece uma relação - lógica - entre as formas e as modalidades, sendo que o fato de que as duas caracterizações dos enunciados não concordam totalmente permite justificar a análise específica que propomos aqui: as modalidades revelam, de uma maneira diferente das formas, o posicionamento do escritor no seu discurso e podem ajudar a estabelecer uma caracterização genérica específica dos discursos.

\section{CONCLUSÃO}

A ausência de diferenças significativas entre os escritores do corpus e os países nele representados justificou a apresentação de análises globais, com dados relativamente amplos, o que permite postular uma certa regularidade na distinção entre os dois gêneros da escrita acadêmica que analisamos, independentemente da língua ou do país. Portanto, a nossa hipótese apresenta uma pertinência razoável: as modalidades enunciativas da inserção do discurso de outrem permitem, em certa medida, caracterizar genericamente tipos de discursos acadêmicos diferentes: os textos de ensino privilegiando a paráfrase e os textos de pesquisa, a metáfrase.

Isso só poderia ser confirmado - ou infirmado - com uma pesquisa em larga escala, que incluísse outras disciplinas e mais sujeitos analisados. Além disso, uma indagação mais abrangente permitiria propor outras comparações, entre disciplinas ou entre países. Como afirmamos anteriormente, não nos propusemos fazê-lo aqui: não temos possibilidade alguma de tirar conclusões definitivas para identificar uma brasilidade ou uma francidade das formas discursivas, carecendo de uma amostra representativa e, sobretudo, de uma hipótese fundada na determinação de uma formação discursiva. No entanto, as diferenças, bem como as semelhanças observadas entre os subcorpora, podem levar a uma indagação sobre como distinguir o que, nos dados, poderia sinalizar, seja uma homogeneização da escrita acadêmica no mundo (incluindo a diferença entre textos de ensino ou de pesquisa), seja a diferença da constituição, na história dos dois países representados no corpus, das relações entre ensino e pesquisa, que possam se inscrever nas modalidades enunciativas da inserção do discurso de outrem nos textos respectivos.

\section{REFERÊNCIAS}

ASSIS J. A. “Como é que eu faço então pra minha voz aparecer no texto?” Marcas da apropriação de gêneros acadêmicos no processo de letramento da/na universidade. In: ABREU-TARDELLI, L. S.; KOMESU, F. C. (Org.). Letramentos e gêneros textuais/discursivos. Aproximações e distanciamentos. Belo Horizonte: PUC Minas, 2018, p.52-68.

AUTHIER-REVUZ, J. Hétérogénéité montrée et hétérogénéité constitutive : éléments pour une approche de l'autre dans le discours. DRLAV, Paris, n. 26, p. 91-151, 1982.

BAKHTIN, M. Estética da criação verbal. Tradução de Paulo Bezerra. São Paulo: Martins Fontes, 2011. BALLY, C. Linguistique générale et linguistique française. Berne: Francke, 1965.

BART, D.; DAUNAY, B. Les entrées en matière non théoriques dans des mémoires de master et des articles de revues. Linguagem \& Ensino, Pelotas, v. 22, n. 3, p. 906-932, jul.-set. 2019.

BEACCO, J.-C.; MOIRAND, S. Autour des discours de transmission des connaissances. Langages, Paris, n.117, p. 32-53,1995. Disponível em: https://www.persee.fr/doc/lgge_0458-

726x_1995_num_29_117_1704. Acesso em: 21 ago. 2019. 
BOCH, F.; RINCK, F. Pour une approche énonciative de l'écrit scientifique. Lidil, Grenoble, n.41, p.514, 2010. Disponível em: https://journals.openedition.org/lidil/3004. Acesso em: 21 ago. 2019.

BOCH, F.; GROSSMANN, F. Referir-se ao discurso do outro: alguns elementos de comparação entre especialistas e principiantes. Scripta, Belo Horizonte, n. 6/11, p. 97-108, 2002. Disponível em: http://periodicos.pucminas.br/index.php/scripta/article/view/12452. Acesso em: 21 ago. 2019.

BOREL, M.-J. Discours explicatifs. Travaux du Centre de Recherches Sémiologiques de Neuchâtel, Neuchâtel, n. 36, p.18-41, 1980.

DAUNAY, B. La paraphrase dans l'enseignement du français. Neuchâtel: Peter Lang, 2002.

DAUNAY, B. La métalepse du lecteur ou la porosité du métatexte. Cahiers de Narratologie, Nice, n.32, 2017. Disponível em: https://journals.openedition.org/narratologie/7855. Acesso em: 21 ago. 2019.

DAUNAY, B.; DELCAMBRE, I. Les modalités énonciatives de la reformulation. Comparaison entre écriture d'enseignement et de recherche, Langues, cultures et sociétés, Rabat, n. 2/1, p. 23-37, 2016. Disponível em:

https://revues.imist.ma/index.php?journal=LCS\&page=article\&op=view\&path\%5B $\% 5 \mathrm{D}=5783$. Acesso em: 21 ago. 2019.

DAUNAY, B.; DELCAMBRE, I. Les modalités énonciatives de la reprise du discours d'autrui dans les écrits de recherche et les écrits didactiques. Scripta, Belo Horizonte, n. 21/43, p. 37-64, 2017. Disponível em: http://periodicos.pucminas.br/index.php/scripta/article/view/14232/12818. Acesso em: 21 ago. 2019.

DELCAMBRE, I. Formes diverses d'articulation entre discours d'autrui et discours propre. Analyse de commentaires de textes théoriques. Lidil, Grenoble, n. 24, p.135-166, 2001.

DOURY, M.. La fonction argumentative des échanges rapportés. In LÓPEZ-MUÑOZ, J. M.,

MARNETTE, S.; ROSIER L. (Org.). Le Discours rapporté dans tous ses états. Paris: L'Harmattan, 2004, p. 254-264.

DUCROT, O. O dizer e o dito. Campinas: Pontes, 1987.

FLOREZ, M. La citation positionnée dans l'écrit scientifique. In : TUTIN, A.; GROSSMANN F. (Org.). L'écrit scientifique. Du lexique au discours. Rennes: Presses Universitaires de Rennes, 2013. p. 67-84.

FLØTTUM K.; DAHL, T.; KINN, T. Academic Voices. Across languages and disciplines.

Amsterdam/Philadelphia: John Benjamins, 2006.

FLØTTUM, K. Moi et autrui dans le discours scientifique : l'exemple de la négation ne... pas. In: BRES J. et al., Dialogisme et polyphonie. Bruxelles: De Boeck, 2005, p. 323-337.

FOUCAULT, M. A arqueologia do saber. Trad. de Luiz Felipe Baeta Neves. Rio de Janeiro: Forense Universitária, 2012.

GROSSMANN, F. Les modes de référence à autrui chez les experts : l'exemple de la Revue Langages. Faits de Langue, Berne, n.19, p. 225-262, 2002.

GROSSMANN, F.; RINCK, F. La surénonciation comme norme du genre : l'exemple de l'article de recherche et du dictionnaire en linguistique. Langages, Paris, n.156, p.34-50, 2004. Disponível em: https://www.persee.fr/doc/lgge_0458-726x_2004_num_38_156_962. Acesso em: 21 ago. 2019.

HYLAND, K. Academic Attribution: Citation and the Construction of Disciplinary Knowledge. Applied Linguistics, Oxford, n. 20/3, p. 341-367, 1999.

MAINGUENEAU D. L'Analyse du discours. Introduction aux lectures de l'archive. Paris: Hachette, 1991.

MAINGUENEAU, D. Os termos-chave da Análise do Discurso. Belo Horizonte: UFMG, 2006.

NØLKE, H.; FLØTTUM; K.; NORÉN, C. ScaPoLine. La théorique scandinave de la polyphonie linguistique. Paris: Kimé, 2004.

ORLANDI E. P. Eu, tu, ele. Discurso e real da história. Campinas: Pontes, 2017.

PLANTIN, C. Argumentação. Tradução de Marcos Marcionilo. São Paulo: Parábola, 2008.

PLANTIN, C. Essais sur l'argumentation. Paris: Kimé, 1990.

POLLET M.-C.; GLORIEUX C. (Org.). Argumenter dans les écrits scientifiques. Namur: Presses universitaires de Namur, 2016.

RABATEL, A. L'effacement énonciatif dans les discours rapportés et ses effets pragmatiques. Langages, Paris, n.156, p.3-17, 2004. Disponível em: https://www.persee.fr/doc/lgge_0458-

726x_2004_num_38_156_960. Acesso em: 21 ago. 2019. 
RABATEL, A. Les enjeux des postures énonciatives et de leur utilisation en didactique. Éducation et didactique, Rennes, n.1/2, p. 89-116, 2007. Disponível em: https://journals.openedition.org/educationdidactique/162. Acesso em: 21 ago. 2019.

RABATEL, A. Os desafios das posturas enunciativas e de sua utilização em didática. EID\&A (Revista Eletrônica de Estudos Integrados em Discurso e Argumentação), Ilhéus, n.12, p.191-233, 2016.

Disponível em: http://periodicos.uesc.br/index.php/eidea/article/view/1328. Acesso em: 21 ago. 2019.

RINCK F.; BOCH F.; ASSIS J. A. (Org.). Letramento e formação universitária. Formar para a escrita e pela escrita. Campinas: Mercado de Letras, 2015.

RINCK, F. L'article de recherche en Sciences du Langage et en Lettres. Figure de l'auteur et approche disciplinaire du genre. Thèse de doctorat, Université de Grenoble, 2006.

ROBERTS, M. Biblical epic and rhetorical paraphrase in late Antiquity. Liverpool: Francis Cairns, 1985.

RODRIGUES, D. Discurso relatado: entre a semelhança e a diferença. Mélanges Crapel. Nancy, n. 37, p.119-128, 2016. Disponível em: http://www.atilf.fr/spip.php?article4087. Acesso em: 21 ago. 2019.

SWALES, J. Genre Analysis. English in Academic and Research Settings. Cambridge: Cambridge University Press, 1990.

TUTIN, A.; GROSSMANN, F. (Org). L'écrit scientifique. Du lexique au discours. Autour de Scientext. Rennes: Presses universitaires de Rennes, 2013.

VINCENT, D; DUBOIS, S. Le discours rapporté au quotidien. Québec: Nuit blanche, 1997.

VOLÓCHINOV, V. Marxismo e filosofia da linguagem. Problemas fundamentais do método sociológico na ciência da linguagem. Tradução, notas e glossário Sheila Grillo e Ekaterina Vólkova Américo. São Paulo: Editora 34, 2017.

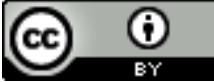

Este texto está licenciado com uma Licença Creative Commons Atribuição 4.0 Internacional. 